\title{
Mind-Body Interactions and Mindfulness Meditation in Diabetes
}

\author{
Gagan Priya ${ }^{1}$ and Sanjay Kalra² \\ 1. Fortis Hospital, Mohali, India; 2. Bharti Hospital, Karnal, India
}

$\mathrm{D}$ abetes is associated with significant psychological distress. It is, therefore, important to ensure the physical and emotional as well as psychosocial wellbeing of individuals living with diabetes. Meditation-based strategies have been evaluated for their complementary role in several chronic disorders including depression, anxiety, obesity, hypertension, cardiovascular disease and diabetes. The practice of meditation is associated with reduction in stress and negative emotions and improvements in patient attitude, health-related behaviour and coping skills. There is increased parasympathetic activity with reduction in sympathetic vascular tone, stress hormones and inflammatory markers. Additionally, several studies evaluated the role of mindfulness-based stress reduction in diabetic individuals and demonstrated modest improvements in body weight, glycaemic control and blood pressure. Thus, mindfulness meditation-based intervention can lead to improvements across all domains of holistic care - biological, psychological and social. Though most of these studies have been of short duration and included small numbers of patients, meditation strategies can be useful adjunctive techniques to lifestyle modification and pharmacological management of diabetes and help improve patient wellbeing.

\section{Keywords}

Meditation, mindfulness meditation, mindfulness-based stress reduction, diabetes, diabetes distress, holistic care, stress reduction

Disclosure: Gagan Priya and Sanjay Kalra have nothing to disclose in relation to this article.

Review Process: Double-blind peer review.

Compliance with Ethics: All procedures were followed in accordance with the responsible committee on human experimentation and with the Helsinki Declaration of 1975 and subsequent revisions.

Authorship: All named authors meet the criteria of the International Committee of Medical Journal Editors for authorship for this manuscript, take responsibility for the integrity of the work as a whole and have given final approval for the version to be published.

open Access: This article is published under the Creative Commons Attribution Noncommercial License, which permits any non-commercial. use, distribution, adaptation and reproduction provided the original author(s) and source are given appropriate credit. (c) The Authors 2018.

Received: 22 December 2017

Accepted: 26 February 2018

Citation: European Endocrinology. 2018;14(1):35-41

Corresponding Author: Gagan Priya, Department of Endocrinology, Fortis Hospital, Phase 8, Mohali, 160059 India. E: gpriya77@gmail.com

Support: No funding was received for

the publication of this article.
'We are what we think. All that we are arises with our thoughts... Be the witness of your thoughts.' - Gautama Buddha

The biomedical approach in modern medicine focuses on disease as a deviation from the norm of measurable biological variables. The social, psychological and emotional dimensions of health are largely ignored. However, it is not appropriate to designate diseases into distinct categories of physical or mental ailments. A patient's perception of disease does not follow this clear divide between the mind and the body. ${ }^{2}$ Most physical disorders have a strong psychological, emotional and mental impact which determines patient experience and his/her reaction to it. Similarly, most mental ailments have a strong somatic component that needs to be paid attention to. ${ }^{3}$ Holistic care, therefore, must focus on both physical as well as psychosocial health.

The biomedical model has since been replaced by the more humanistic and patient-centred 'biopsychosocial' model in the 21st century, with a focus on the patient at each level - biological, psychological and social. ${ }^{3}$ It involves the integration of disease pathology with the patient's experiences and perceptions, social interactions and patient-doctor communication. An understanding of this biopsychosocial model and its implementation is particularly relevant in the management of chronic metabolic disorders such as obesity, diabetes, hypertension, metabolic syndrome, polycystic ovary syndrome, non-alcoholic fatty liver disease and cardiovascular disorders, where patient attitude and behaviour, lifestyle modification, stress management and long-term adherence to therapy hold the key to successful outcomes.

Stress has been defined as any uncomfortable emotional experience accompanied by predictable biochemical, psychological and behavioural changes directed towards adaptation to or removal of the stressor. ${ }^{4}$ While positive psychological stress or eustress can lead to motivation and appropriate action, negative psychological stress or distress can have significant impact on neuroendocrine, cardiovascular, immune and central nervous systems. ${ }^{4}$ Indeed, diabetes and its comorbidities are associated with significant psychological distress. ${ }^{5}$ On one hand, chronic stress, negative mood and cognition are strong risk factors for development of obesity, diabetes, hypertension and cardiovascular disease. ${ }^{6}$ At the same time, living with diabetes requires significant adaptation and excellent coping skills. There is a high prevalence of anxiety and depression in diabetic individuals and depression often tends to be severe but ignored, unrecognised and unaddressed. ${ }^{7}$ Using the Diabetes Distress Scale, Fischer et al. reported a high prevalence of diabetes distress among adults with type 2 diabetes and this was associated with poorer outcomes in relation to lifestyle modification, self-efficacy and glycaemic control. ${ }^{8}$ Additionally, there may be associated eating disorders and substance abuse. Diabetic individuals often report disease-related stigmatisation, in both personal and professional domains. ${ }^{9}$ Hence, mind-body therapies that aim at physical, mental and emotional wellbeing may have a significant role in reduction of diabetes distress, 
improvement of health behaviours and overall wellbeing of individuals living with diabetes.

We performed a PubMed search for the terms 'meditation', 'mindfulness meditation', 'mindfulness', 'mindfulness-based stress reduction' or 'mindfulness-based intervention' and 'diabetes' from January 1984 to November 2017. The search revealed 154 articles. After reading through the abstracts, we selected controlled trials of mindfulness-based interventions in diabetes for the purpose of this review.

\section{Meditation - historical perspectives}

Meditation has been practiced since ancient times, with the earliest references going back to the vedas. It has formed an integral part of Eastern religions including Buddhism, Hinduism, Jainism and Sikhism. ${ }^{10}$ Meditation has had varied interpretations in different cultures and includes a wide range of different techniques and practices that ultimately involve self-regulation of the mind. ${ }^{11}$ Transcendental meditation constitutes an important component of several Eastern religions such as Hinduism, Buddhism and Jainism. Meditation practices such as mindfulness, loving kindness and insight form the fundamentals of Buddhist meditation. The ancient Indian science of yoga, the chinese arts of qigong and tai chi and the Japanese art of reiki are meditation-based movement therapies. Western religions have also incorporated meditation into their practices, such as hesychasm, Western Christian meditation and the Islamic practice of Dhikr.

Meditation was primarily considered a tool for the attainment of spiritual salvation and practised by saints and ascetics. However, scientific enquiry into meditation began in the early 1900s and the approach focused on secular meditation techniques as a strategy for stress reduction, mental relaxation and self-improvement. Meditation is a state of contemplation, focused attention and reflection aimed at improving spiritual, mental and emotional wellbeing. While there has been no uniformly accepted definition and the term 'meditation' may have different interpretations, the following definition proposed by Walsh and Shapiro has been widely accepted in clinical psychology:

'M]editation refers to a family of self-regulation practices that focus on training attention and awareness in order to bring mental processes under greater voluntary control and thereby foster general mental well-being and development and/or specific capacities such as calm, clarity, and concentration. ${ }^{\prime 11}$

The core components of meditation practice include focused attention, self-regulation of emotions and self-awareness.

Over the decades, several meditation-based techniques have been developed and incorporated into cognitive and psychological therapies. These include mindfulness-based stress reduction (MBSR), mindfulnessbased cognitive therapy (MBCT), mindfulness-based art therapy (MBAT), acceptance and commitment therapy (ACT), dialectical behaviour therapy (DBT) and mode deactivation therapy (MDT), among others. Mindfulness-based stress reduction is a well-developed, 8-week program that incorporates mindfulness meditation and yoga. ${ }^{12-14}$

\section{Mindfulness meditation}

Mindfulness is the psychological process of bringing one's attention to the present moment. Mindfulness meditation refers to the state of awareness that arises through paying attention, on purpose, in the present moment, non-judgementally. ${ }^{12}$ 'Mindfulness of breathing' is a simple practice where the practitioner can sit in any position and focus on the breath as he/she inhales and exhales. Steady attention is paid to the breath coming in and out, and if the mind drifts away to any sensation, thought or emotion, it is gently brought back to the observation of breath. The awareness can, similarly, be focused on body parts and sensations, physical functions such as walking or internal experiences such as thoughts, feelings and emotions. ${ }^{14}$ The practitioner simply observes all feelings/thoughts/sensations that arise, both pleasant and unpleasant, without dwelling on them or judging them. Transcendental meditation involves focusing the mind silently on a specific mantra (repetition of words, syllables or phrases). Loving kindness or equanimity meditation involves the cultivation of compassion for self and others.

The mind is thus trained in meditation to become aware of the outer world and the inner mental and emotional state, in the present moment, without attempts to control or suppress it or respond to it. ${ }^{15}$ Mindfulness meditation, transcendental meditation and meditative movement therapies such as yoga, tai chi and qigong have received the greatest attention in clinical psychology and healthcare. ${ }^{16,17}$ Mindfulness meditation has been incorporated into psychology and psychiatry practices for several chronic disorders pertaining to both mental and physical domains. Benefits have been demonstrated in depression, anxiety, eating disorders, sleep disorders, fibromyalgia, chronic pain syndrome, rheumatoid arthritis, cancer, HIV/AIDS, diabetes, hypertension, cardiovascular diseases and substance abuse..$^{18-23}$

\section{Role of mindfulness meditation in diabetes care - the evidence}

The practice of meditation is associated with greater voluntary control of the mind and emotions and cultivation of positive mental attributes such as calmness, serenity, concentration, joy and love and reduction of negative emotions such as anxiety, depression, anger, fear or hatred. ${ }^{11}$ Thus, it can reduce reaction to stress and improve coping skills, attention, awareness, memory, sensory perception and cognitive regulation of emotions and help develop a more coherent sense of self and identity. ${ }^{24}$ In a Swedish population-based study, the practice of mindfulness in general was associated with an improved perception of wellbeing among individuals. ${ }^{25}$

\section{Evidence - basic science}

Meditation seems to have effects on multiple regions of the brain, involving large-scale neural networks in the cortex, subcortical grey and white matter, cerebellum and brainstem. These have been extensively reviewed by Tang et al. ${ }^{26}$ Several cross-sectional studies and short-term longitudinal studies using structural and functional magnetic resonance imaging (MRI) have reported both functional and structural changes in brain in long-term meditators as well as beginners of meditation practice. such neuroplasticity changes have been reported in the frontopolar cortex, sensory cortices, anterior cingulate cortex, midcingulate cortex, orbitofrontal cortex, insula, superior longitudinal fasciculus, corpus callosum, hippocampus, temporoparietal junction, frontolimbic network and default mode network structures. ${ }^{26-27}$ The neuroplasticity changes reported include increased activation of certain regions and reduced activation of others, increase in cortical thickness and grey matter density and volume. ${ }^{26}$ However, it is not clearly understood how these functional and structural changes relate to improvements in cognitive, affective and social functions and overall wellbeing. Some of the neuroplasticity changes that have been related to improved attention regulation, emotional regulation and self-awareness include:

1. Attention regulation: anterior cingulate cortex and fronto-insular cortex are involved in attention regulation and cognitive processing. Enhanced activation of the anterior cingulate cortex has been 
reported in long-term meditators during focused attention. ${ }^{28}$ Other regions demonstrating enhanced activation in relation to attention include the prefrontal cortex and parietal attention regions Mindfulness meditation has also been associated with greater cortical thickness and decreased age-related decline in grey matter volume of putamen. ${ }^{26}$

2. Emotion regulation: meditation is associated with reduced emotional reaction and negative affect to stressors, reduced physiological reactivity and faster return to positive mood state. Mindfulness results in decreased activation of amygdala in response to emotional stimuli and has been associated with greater activation of dorsomedial and dorsolateral prefrontal cortex in beginners, but the reverse is seen in experienced meditators. This may be because beginners need to overcome habitual ways of reacting to emotions and therefore exhibit greater activation of prefrontal cortex. ${ }^{26}$ Functional alterations have also been demonstrated in regions involved in motivation and reward process, including increased activity in the putamen and caudate during resting state.

3. Self-awareness: mindfulness is associated with a more positive representation of self. The default mode network which involves midline structures, including medial prefrontal cortex, posterior cingulate cortex, anterior precuneus and inferior parietal lobule, is widely believed to be involved in self-referential processing. Functional MRI has demonstrated reduced activity of the default mode network in meditators. ${ }^{28}$ Increased connectivity of default mode network with ventromedial prefrontal cortex has been seen in experienced meditators and this may be involved in greater cognitive control. Mindfulness is also associated with increased awareness of the present moment. Insula has been shown to be strongly activated following mindfulness training and experienced meditators have increased cortical thickness of insula. ${ }^{26}$

4. Stress reduction: a potential mediator of the benefits of mindfulness on brain function seems to be stress reduction. ${ }^{26}$ Increased brain activity in the prefrontal cortical regions involved in stress regulation and decreased activity in regions involved in fight-or-flight response, such as the amygdala and anterior cingulate cortex, has been demonstrated after short-term meditation sessions. Several studies have also demonstrated a positive effect of mindfulness on biomarkers of stress such as serum cortisol..$^{29}$ Cortisol and brainderived neurotrophic factor may be the facilitators of these functional and morphological changes. The prefrontal cortex, hippocampus, amygdala and other areas are vulnerable to stress-induced functional and structural remodelling. Meditation is associated with reduced sympathoadrenal activity and an increase in parasympathetic tone and reduced secretion of stress hormones. There is also reduced secretion of inflammatory markers such as interleukin-6, C-reactive protein and tumour necrosis factor $\alpha .^{27,30}$

It remains to be determined how the neuroplasticity changes seen in long-term meditators differ from beginners. Using functional near-infrared spectroscopy, Gundel et al. demonstrated that meditation experts had different lateralisation patterns in resting state, which associated with amplified left hemisphere and in response to the sound of a meditation bowl, which was associated with amplified right hemisphere. Even beyond the meditative task, areas including Brodman's area 39, 40, 44 and 45, had increased brain activity, thus suggesting that meditation induced possible long-term changes in brain, explaining its positive effect on health. ${ }^{31}$

\section{Evidence - clinical science}

Meditation practices such as MBSR can be an important group intervention in patients with diabetes to reduce psychological distress, improve mood and develop positive coping skills. ${ }^{32}$ They have the potential to influence the patient experience and perception of the burden of diabetes and can help encourage health behaviours related to primary, secondary and tertiary prevention. ${ }^{33}$ Randomised studies have demonstrated that MBSR resulted in significant improvements in depression and anxiety and improved self-care behaviour. In Table 1, we enumerate the effects of mindfulness-based strategies on diabetes and related outcomes reported in various studies. Mindfulness-based stress reduction was associated with significant improvements in diabetes distress, weight, glycaemic control and blood pressure control. Thus, it results in reduced heart rate variability, vascular resistance and ventricular workload. .64,47 $^{6}$ Loving kindness meditation can lead to improvements in relationship satisfaction and prosocial behaviour. A recent systematic review evaluated the evidence from clinical trials examining the effect of mindbody therapies as adjunctive complementary strategies in metabolic syndrome. Meditation-based therapies were associated with significant improvements in blood pressure, glycaemic control, body weight and waist circumference. ${ }^{48}$ In a meta-analysis of eight randomised controlled trials involving hypertensive subjects, transcendental meditation was associated with a reduction in systolic blood pressure of $4.7 \mathrm{mmHg}$ and diastolic blood pressure of $3.2 \mathrm{mmHg}$ compared to control groups. ${ }^{45}$ Significant reductions in body weight have been reported in a metaanalysis of mindfulness-based interventions for weight loss and this may have clinical relevance in diabetes care. ${ }^{49}$ To summarise, mindfulness interventions have demonstrated impact on a broad range of outcomes relating to all domains of holistic care in diabetes - biological, psychological and also social, as depicted in Figure 1.

An important question that needs to be addressed is the amount of mindfulness intervention necessary to experience benefits. Even three to four brief sessions of 5-10 minutes of guided meditation have been shown to reduce negative affect, but most studies have been conducted over 4-8-week programs. ${ }^{18}$ Moreover, most studies are limited by small sample size, short duration and a lack of adequate control group. Therefore, these studies carry a high risk of bias. In a meta-analysis, it was demonstrated that there existed a strong bias towards publication of positive results in meditation studies. ${ }^{28}$ Additionally, it can be argued that several trials of physical activity and lifestyle intervention are themselves associated with significant improvements in metabolic parameters and overall wellbeing

\section{Unwanted effects of meditation}

It is important to evaluate the possible negative effects of mindfulness practices and identify individuals who may succumb to such unwanted effects before recommending widespread use of mindfulness meditation in diabetes. Some studies have evaluated the unwanted effects of meditation. ${ }^{50,51}$ These included emotional pain, self-criticism, fear, anxiety, lack of motivation, boredom, disorientation, insomnia, feeling of alienation or lacking something..$^{50}$ Most investigators have suggested that these adverse effects are mild and transitory and did not lead to discontinuation of meditation and may be a part of the psychotherapeutic effect. ${ }^{50}$ Rarely, individuals may experience more severe adverse reactions with more intensive mindfulness training such as the triggering of major depressive episode or psychosis, ${ }^{52}$ posttraumatic stress disorder, ${ }^{53}$ and epileptic attacks. ${ }^{54}$ Hence, caution is needed when initiating people with psychosis, seizures, post-traumatic stress or severe depression into mindfulness. ${ }^{27}$ However, most clinical studies involve low intensity meditation practices and such adverse effects are not often reported unlike with more intensive traditional meditation techniques which can be psychologically challenging. Future interventional studies should carefully assess the negative effects of 
Table 1: Summary of clinical studies of mindfulness meditation in diabetes

\begin{tabular}{|c|c|c|}
\hline Author, year & Study design & Results \\
\hline Rosenzweig et al., $2007^{34}$ & $\begin{array}{l}\text { Prospective observational study, } 14 \text { adults with T2D } \\
\text { participating in MBSR program over } 1 \text { month. }\end{array}$ & $\begin{array}{l}\text { 11/14 patients completed the intervention. } \mathrm{HbA}_{1 \mathrm{c}} \text { reduced by }-0.48 \% \\
\text { and mean arterial pressure by }-6 \mathrm{mmHg} \text {, no change in weight at } 1 \\
\text { month. Significant improvement in depression, anxiety and general } \\
\text { psychological distress. }\end{array}$ \\
\hline $\begin{array}{l}\text { Kopf and Hartmann et al., } \\
\text { HEIDIS trial, } 2014^{35,36}\end{array}$ & $\begin{array}{l}\text { In an open-label, randomised study, } 110 \text { patients with } \\
\text { T2D and early diabetic kidney disease (microalbuminuria) } \\
\text { were randomised to 8-week MBSR ( } n=53 \text { ) or standard care } \\
\text { ( } n=57 \text { ). Participants met once weekly for } 8 \text { weeks followed } \\
\text { by a booster session after } 6 \text { months and long-term effects } \\
\text { were assessed at 1, } 2 \text { and } 3 \text { years. } \\
\text { Patient health questionnaire PHQ-9 was used to assess } \\
\text { depression score and stress scores. } \\
\text { Subjective health was assessed using short form health } \\
\text { survey (SF-12). }\end{array}$ & 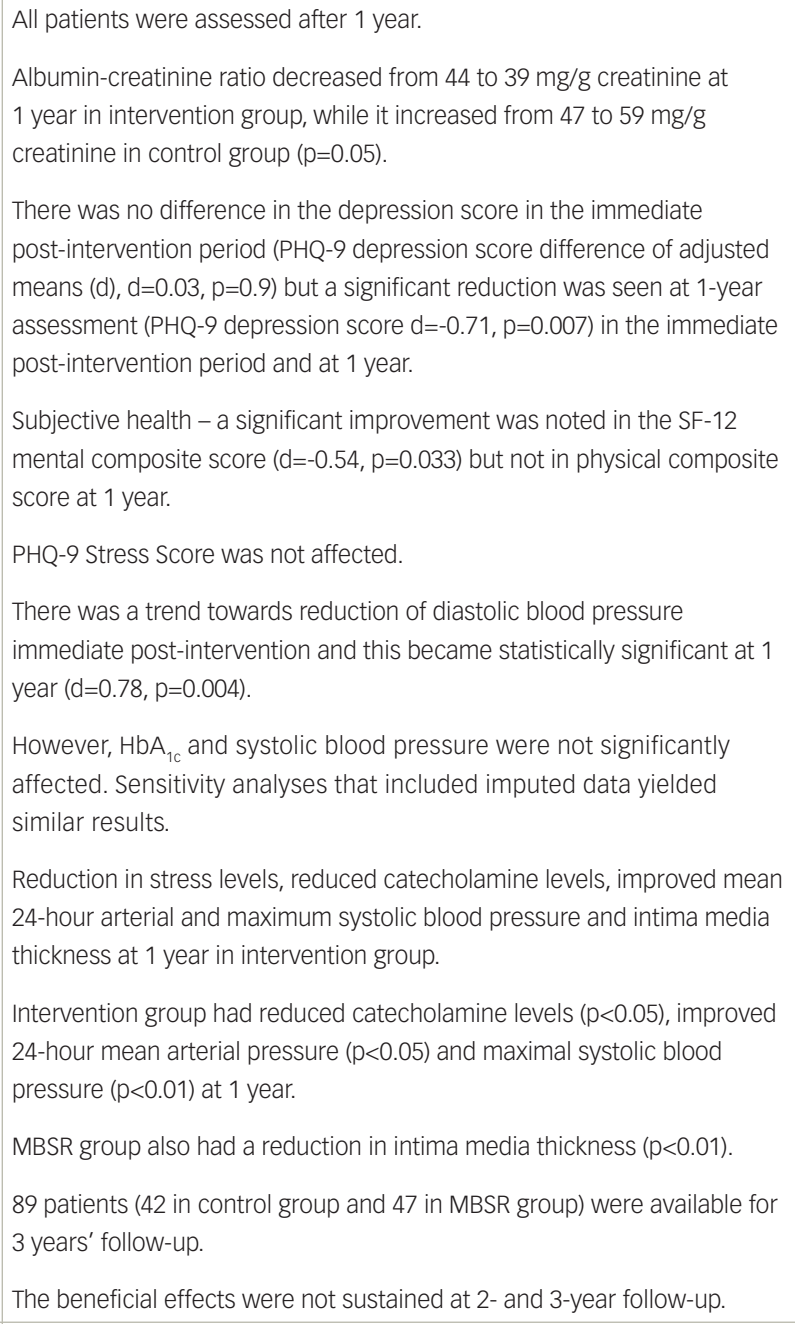 \\
\hline $\begin{array}{l}\text { Rungreangkulkij et al., } \\
2011^{37}\end{array}$ & $\begin{array}{l}\text { A quasi-experimental study using intervention group and } \\
\text { matched controls. } \\
62 \text { patients with T2D and with depressive symptoms } \\
\text { were assigned to Buddhist group therapy and meditation } \\
\text { practices ( } n=32 \text { ) versus control group which received } \\
\text { standard treatment only ( } n=32 \text { ). } \\
\text { Intervention group underwent weekly 2-hour sessions for } 6 \\
\text { weeks plus home meditation practices. }\end{array}$ & $\begin{array}{l}\text { After } 6 \text { months, there was improvement in depression score in the } \\
\text { meditation group. In the intention-to-treat analysis, relative risk of } \\
\text { depressive symptoms was } 6.5(95 \% \mathrm{Cl} 1.4,30.60) \text { between experimental } \\
\text { and control groups. } \\
\text { Qualitative data reported greater acceptance of current living condition in } \\
\text { the meditation group. }\end{array}$ \\
\hline Keyworth et al., 2014 ${ }^{38}$ & $\begin{array}{l}\text { Pilot study. } 40 \text { adults with diabetes and coronary heart } \\
\text { disease underwent a 6-week meditation and mindfulness } \\
\text { intervention program. } \\
\text { The Penn State Worry Questionnaire (PSWQ) was used } \\
\text { to assess pathological worry and the White Bear } \\
\text { Suppression Inventory (WBSI) was used to measure } \\
\text { thought suppression. } \\
\text { Qualitative effects on acceptability, feasibility and user } \\
\text { experience were assessed using a focus group ( } \mathrm{n}=11) \\
\text { and in-depth interviews ( } \mathrm{n}=16 \text { ). }\end{array}$ & $\begin{array}{l}\text { Intervention was highly acceptable ( }>90 \% \text { completed } \geq 5 \text { sessions). } \\
\text { There was significant improvement in PSWQ before and after intervention: } \\
\text { mean }=48.55 \pm 14.14 \text { and } 42.84 \pm 12.05 \text {, respectively ( } p<0.001 \text { ). } \\
\text { Similar improvements were noted in WBSI scores before and after } \\
\text { intervention: mean }=49.53 \pm 12.44 \text { and } 46.34 \pm 11.47 \text { ( } p=0.015 \text { ). } \\
\text { In the qualitative assessment, meditation was associated with improved } \\
\text { sleep, greater relaxation, better acceptance of illness and illness } \\
\text { experience. }\end{array}$ \\
\hline
\end{tabular}


Table 1: Summary of clinical studies of mindfulness meditation in diabetes (continued)

\begin{tabular}{|c|c|c|}
\hline Author, Year & Study design & Results \\
\hline Gainey et al., $2016^{40}$ & $\begin{array}{l}23 \text { patients with T2D were randomised to traditional } \\
\text { walking exercise or Buddhism-based walking meditation } \\
\text { exercise. } \\
\text { Both groups followed a 12-week exercise program that } \\
\text { involved walking on a treadmill at exercise intensity of } \\
50-70 \% \text { maximum heart rate, for } 30 \text { min/session, three } \\
\text { times/week. Meditation group meditated on the sound } \\
\text { 'Budd-Dha' while exercising. }\end{array}$ & $\begin{array}{l}\text { Decrease in fasting blood glucose and maximal oxygen consumption in } \\
\text { both groups at } 12 \text { weeks }(p<0.05) \text {. } \\
\text { Significant decrease in } \mathrm{HbA}_{1 c^{\prime}} \text { systolic and diastolic blood pressure seen } \\
\text { only in walking meditation group. } \\
\text { Flow-mediated vasodilatation improved in both groups ( } p<0.05) \text {, but } \\
\text { arterial stiffness improved only in walking meditation group. } \\
\text { Blood cortisol levels reduced }(p<0.05) \text { in walking meditation group. }\end{array}$ \\
\hline Chaiopanont et al., $2008^{41}$ & $\begin{array}{l}\text { Quasi-experimental study that included } 50 \text { patients with } \\
\text { T2D (11 males, } 39 \text { females). All participants were trained } \\
\text { to practice sitting breathing meditation after breakfast for } \\
2 \text { weeks. }\end{array}$ & $\begin{array}{l}\text { Significant reduction was seen in postprandial plasma glucose in the } \\
\text { second week visit }(-19.26 \pm 30.99 \mathrm{mg} / \mathrm{dl}, \mathrm{p}<0.001) \text { and third week visit } \\
(-17.64 \pm 25.48 \mathrm{mg} / \mathrm{dl}, \mathrm{p}<0.001) \text {. } \\
\text { Systolic blood pressure was also significantly reduced in second visit } \\
(-6.49 \pm 11.77 \mathrm{mgHg}, \mathrm{p}<0.001) \text { and diastolic blood pressure was reduced } \\
\text { in the third visit }(-3.04 \pm 9.79, \mathrm{p}<0.05) \text {. }\end{array}$ \\
\hline Jung et al., $2015^{42}$ & $\begin{array}{l}\text { Cluster randomised trial design. } \\
56 \text { adults with diabetes were randomised to patient } \\
\text { education, MBSR or walking exercise groups over } 8 \text { weeks. } \\
\text { Diabetes-related distress was assessed by Diabetes } \\
\text { Distress Scale. } \\
\text { Psychological response to stress was measured by } \\
\text { Perceived Stress Response Inventory. } \\
\text { Other outcomes included fasting glucose, serum cortisol, } \\
\text { serum plasminogen activator inhibitor-1 (PAl-1) and tissue } \\
\text { plasminogen activator (t-PA). }\end{array}$ & $\begin{array}{l}\text { No difference between the three groups in relation to diabetes distress, } \\
\text { psychological response to stress, glycaemic control or vascular } \\
\text { inflammation (t-PA). } \\
\text { MBSR group and walking exercise groups had statistically significant } \\
\text { reductions in plasma cortisol }(-2.53 \pm 3.96 \mu \mathrm{g} / \mathrm{dl} \text { and }-4.51 \pm 5.69 \mu \mathrm{g} / \mathrm{dl}) \\
\text { from baseline. } \\
\text { Significant reductions in PAl-1 levels were seen in all three intervention } \\
\text { groups (-8.94 } \pm 10.84 \text { in MBSR group, }-11.74 \pm 16-07 \text { in walking exercise } \\
\text { group and }-15.73 \pm 10.86 \mathrm{ng} / \mathrm{ml} \text { in patient education group). }\end{array}$ \\
\hline Rogers et al., $2017^{43}$ & $\begin{array}{l}\text { Meta-analysis of } 15 \text { randomised controlled trials or } \\
\text { prospective cohort studies measuring outcomes of } \\
\text { mindfulness-based interventions in } 560 \text { individuals who } \\
\text { were overweight or obese. }\end{array}$ & $\begin{array}{l}\text { Average weight loss } 4.2 \mathrm{~kg} \text {. } \\
\text { Overall effect size was large for improvement in eating behaviours } \\
\text { (likelihood ratio as calcuated in } \mathrm{G} \text {-test }[\mathrm{g}], \mathrm{g}=1.08 \text { ) and medium for eating } \\
\text { attitudes ( } \mathrm{g}=0.57 \text { ), depression ( } \mathrm{g}=0.64 \text { ) and anxiety ( } \mathrm{g}=0.62 \text { ). } \\
\text { Effect on body mass index ( } \mathrm{g}=0.47 \text { ) and metacognition ( } \mathrm{g}=0.38 \text { ) was small. } \\
\text { Similar benefits persisted when only higher quality randomised controlled } \\
\text { trials were included. }\end{array}$ \\
\hline Abbott et al., $2014^{44}$ & $\begin{array}{l}\text { Meta-analysis of eight randomised controlled trials, effect } \\
\text { of MBSR or MBCT, } 578 \text { participants with prehypertension/ } \\
\text { hypertension (three trials), diabetes (two trials), heart } \\
\text { disease (two trials) and stroke (one trial). }\end{array}$ & $\begin{array}{l}\text { Significant reduction in stress }(-0.36,95 \% \mathrm{Cl}-0.67 \text { to }-0.09 ; \mathrm{p}=0.01) \text {, } \\
\text { depression }(-0.35 ; 95 \% \mathrm{Cl}-0.53 \text { to }-0.16 ; \mathrm{p}=0.003) \text { and anxiety }(-0.50 ; 95 \% \\
\mathrm{Cl}-0.70 \text { to }-0.29 ; \mathrm{p}<0.001) \text {. } \\
\text { Mixed effects on physical outcomes (blood pressure, albuminuria, } \\
\text { stress hormones). }\end{array}$ \\
\hline Anderson et al., $2008^{45}$ & $\begin{array}{l}\text { Meta-analysis of nine randomised controlled trials } \\
\text { comparing blood pressure response to transcendental } \\
\text { meditation technique with control group. Three studies } \\
\text { rates as high quality and three as acceptable quality. } \\
\text { Effect of transcendental meditation on blood pressure } \\
\text { assessed by random-effects meta-analysis model. }\end{array}$ & $\begin{array}{l}\text { Transcendental meditation was associated with significant reduction in } \\
\text { systolic blood pressure }(-4.7 \mathrm{mmHg}, 95 \% \mathrm{Cl}-7.4 \text { to }-1.9) \text { and diastolic } \\
\text { blood pressure }(-3.2 \mathrm{mmHg}, 95 \% \mathrm{Cl}-5.4 \text { to }-1.3) \text {. } \\
\text { Subgroup analysis of high quality studies showed similar reductions. }\end{array}$ \\
\hline
\end{tabular}

$\mathrm{Cl}=$ confidence interval; $\mathrm{d}=$ difference of adjusted means; $\mathrm{g}=$ likelihood ratio as calculated in $\mathrm{G}$-test; $\mathrm{HbA} 1 \mathrm{C}=$ glycated haemoglobin A1C; $\mathrm{MBCT}=$ mindfulness-based cognitive therapy; MBSR = Mindfulness-based stress reduction; PAI-1 = serum plasminogen activator inhibitor-1; PHQ-9 = Patient Health Questionnaire 9; T2D = type 2 diabetes.

meditation and identify individuals who are more likely to benefit from mindfulness interventions.

\section{Meditation in modern medicine - eminence}

Mind and body practices including meditation are being used by a large number of diabetic patients in many countries of South East Asia as complementary strategies. ${ }^{55}$ The Indian national guidelines for management of diabetes recommend yoga as complimentary therapy which has beneficial effects on various metabolic parameters. ${ }^{55}$ WHO categorises 'mind-body medicine' which includes meditation, prayer, mental healing, yoga, tai chi, art therapy, music therapy and dance therapy as Complementary and Alternative Medicine. In a scientific statement issued in 2013, the American Heart Association recognised that there was Class II B (Level of Evidence B) evidence for recommending transcendental meditation and biofeedback approaches as adjunct to pharmacological therapy of hypertension. The evidence for other meditation techniques and yoga was rated as Class III (Level of Evidence C). ${ }^{56}$ In a recent position statement, the American Heart Association acknowledges that meditation may be considered as an adjunct to lifestyle modification and pharmacological treatment in cardiovascular risk reduction..$^{57}$ 


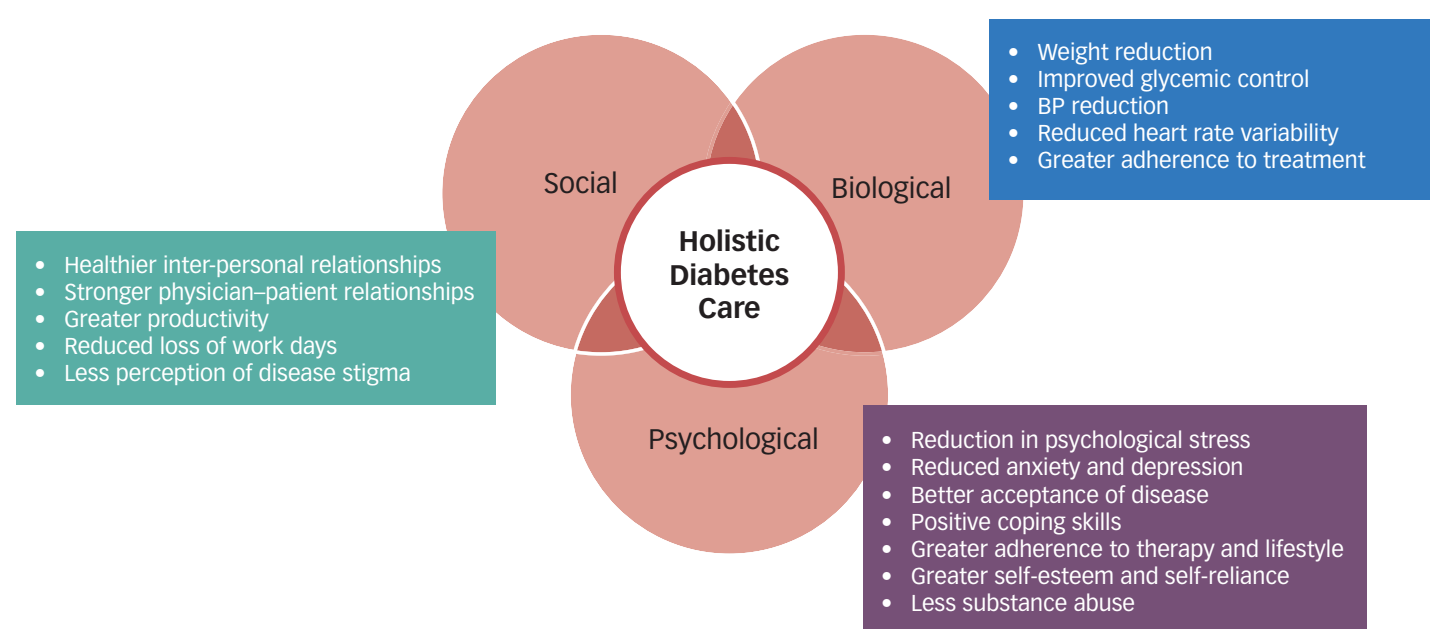

$B P=$ blood pressure

\section{Conclusion}

Mindfulness meditation-based strategies are simple, easy to grasp and practice and do not incur additional cost. Moreover, many individuals may not be able to engage in moderate to vigorous physical activity. This may be due to physical limitations such as osteoarthritis, morbid obesity, cardiovascular or respiratory disease. Meditation-based therapies may offer immediate positive benefits in such individuals. It may also help improve self-care behaviour, self-reliance and self-control. This would result in better quality of life. Therefore, the role of mindfulness meditation needs to be evaluated further in well-conducted studies. $\square$
'If you meditate earnestly, pure in mind and kind in deeds, leading a disciplined life in harmony with the dharma, you will grow in glory. If you meditate earnestly, through spiritual disciplines you can make an island for yourself that no flood can overwhelm.' - Guatama Buddha'
Easwaran E. Essence of the Dhammapada: the Buddha's call to Nirvana, Tomales, CA: Nilgiri Press, 2013.

2. Davidsen AS, Guassora AD, Reventlow S. Understanding the body-mind in primary care. Med Health Care Philos. 2016;19:581-94.

3. Farre A, Rapley T. The new old (and old new) medical model: four decades navigating the biomedical and psychosocial understandings of health and illness. Healthcare (Basel). understandings of

4. Baum A. Stress, intrusive imagery, and chronic distress. Health Psychol. 1990;9:653-75

5. Kalra S, Verma K, Singh Balhara YP. Management of diabetes distress. J Pak Med Assoc. 2017;67:1625-7.

6. Ray IB, Menezes AR, Malur P, et al. Meditation and coronary heart disease: a review of the current clinical evidence. ochsner J. 2014;14:696-703.

7. Katon WJ. The comorbidity of diabetes mellitus and depression Am J Med. 2008;21:S8-15. Suppl. 2.

8. Fischer L, Hessler DM, Polonsky WH, Mullan JT. When is diabetes distress clinically meaningful?: establishing cut points for the Diabetes Distress Scale. Diabetes Care. 2012;35:259-64.

9. Liu NF, Brown AS, Younge MF et al. Stigma in people with type 1 or type 2 diabetes. Clin Diabetes. 2017;35:27-34.

10. Priva G, Kalra S, Dardi IK, et al. Diabetes care: inspiration from Priya G, Kalra S, Dardi IK, et al. Diabetes care: inspir

11. Walsh R, Shapiro SL. The meeting of meditative disciplines and Western psychology: a mutually enriching dialogue. Am Psychol. 2006;61:227-39.

12. Kabat-Zinn J. Full Catastrophe Living: Using the Wisdom of your Body and Mind to Face Stress, Pain and IIIness. New York: Delacourt Press, 1990

13. Zou T, Wu C, Fan $X$. The clinical value, principle, and basic practical technique of mindfulness intervention. Shanghai Arch Psychiatry. 2016;28:121-30.

14. Ludwig DS, Kabat-Zinn J. Mindfulness in medicine. JAMA. 2008;300:1350-2.

15. Whitebird RR, Kreitzer MJ, O'Connor PJ. Mindfulness-based stress reduction and diabetes. Diabetes Spectr. 2009:22:226-

16. Kumar $\mathrm{V}$, Jagannathan $\mathrm{A}$, Philip $\mathrm{M}$, et al. Role of yoga for patients with type II diabetes mellitus: a systematic review and meta-analysis. Complement Ther Med. 2016;25:104-12.

17. Kelley GA, Kelley KS. Meditative movement therapies and health-related quality-of-life in adults: a systematic review of meta-analyses. PLoS One. 2015;10:e0129181. doi: 10.1371/ journal.pone.0129181.

18. Cullen M. Mindfulness-based interventions: an emerging phenomenon. Mindfulness. 2011;2:186-93.

19. Follette $\mathrm{V}$, Palm KM, Pearson AN. Mindfulness and trauma: implications for treatment. J Rat-Emo Cognitive-Behav Ther. 2006;24:45-61.

20. Chiesa A, Serretti A. Mindfulness-based interventions for chronic pain: a systematic review of the evidence. J Altern Complement Med. 2011:17:83-93.

21. Kabat-Zinn J, Lipworth L, Burney R, Sellers W. Four-year followup of a meditation-based program for the self-regulation of chronic pain: treatment outcomes and compliance. Clin J Pain 1986;2:159-73.

22. Veehof MM, Oskam MJ, Schreurs KM, Bohlmeijer ET. Acceptance-based interventions for the treatment of chronic pain: a systematic review and meta-analysis. Pain. 2011;152:533-42.

23. Patil SG. Effectiveness of mindfulness meditation (Vipassana) in the management of chronic low back pain. Indian J Anaesth. 2009;53:158-63.

24. Acevedo BP, Pospos S, Lavretsky H. The neural mechanisms of meditative practices: novel approaches for healthy aging. Curr Behav Neurosci Rep. 2016:3:328-39.

25. Bränström R, Duncan LG Moskowitz IT The association between dispositional mindfulness, psychological well-being, and perceived health in a Swedish population-based sample. Br J Health Psychol. 2011;16:300-16.

26. Tang YY, Hölzel BK, Posner MI. The neuroscience of mindfulness meditation. Nat Rev Neurosci. 2015;16:213-25.

27. Hölzel BK, Lazar SW, Gard T, et al. How does mindfulness meditation work? Proposing mechanisms of action from a conceptual and neural perspective. Perspect Psychol SCI. 2011;6:537-59.

28. Fox KC, Nijeboer S, Dixon ML, et al. Is meditation associated with altered brain structure? A systematic review and meta-analysis of morphometric neuroimaging in meditation practitioners. Neurosci Biobehav Rev. 2014:43:48-73.

29. Creswell JD. Mindfulness interventions. Annu Rev Psychol. 2017:68:491-516.

30. Pascoe MC, Thompson DR, Jenkins ZM, Ski CF. Mindfulness mediates the physiological markers of stress: systematic review and meta-analysis. J Psychiatr Res. 2017;95:156-178.

31. Gundel F, von Spee J, Schneider S, et al. Meditation and the brain - Neuronal correlates of mindfulness as assessed with near-infrared spectroscopy. Psychiatry Res. 2018;271:24-33.

32. Young LA, Cappola AR, Baime MJ. Mindfulness based stress reduction: effect on emotional distress in diabetes. Pract Diabetes Int. 2009;26:222-4.

33. Bonadonna R. Meditation's impact on chronic illness. Holist Nurs Pract. 2003;17:309-319.

34. Rosenzweig S, Reibel DK, Greeson JM, et al. Mindfulness-based stress reduction is associated with improved glycemic control stress reduction is associated with improved glycemic control
in type 2 diabetes mellitus: a pilot study. Altern Ther Health Med. 2007:13:36-8.

35. Hartmann M, Kopf S, Kircher C, et al. Sustained effects of a mindfulness-based stress-reduction intervention in type 2 diabetic patients: design and first results of a randomized controlled trial (the Heidelberger Diabetes and Stress-study). Diabetes Care. 2012;35:945-7.

36. Kopf S, Oikonomou D, Hartmann M, et al. Effects of stress reduction on cardiovascular risk factors in type 2 diabetes patients with early kidney disease - results of a randomized controlled trial (HEIDIS). Exp Clin Endocrinol Diabetes. 2014;122:341-9.

37. Rungreangkulkij S, Wongtakee W, Thongyot S. Buddhist group therapy for diabetes patients with depressive symptoms. Arch Psychiatr Nurs. 2011:25:195-205.

38. Keyworth C, Knopp J, Roughley K, et al. A mixed-methods pilot study of the acceptability and effectiveness of a brief meditation and mindfulness intervention for people with diabetes and coronary heart disease. Behav Med. 2014;40:53-64.

39. Teixeira $E$. The effect of mindfulness meditation on painful diabetic neuropathy in adults older than 50 years. Holist Nurs Pract. 2010;24:277-83.

40. Gainey A, Himathongkam T, Tanaka H, Suksom D. Effects of Buddhist walking meditation on glycemic control and vascular function in patients with type 2 diabetes. Complemet Ther Med. 2016;26:92-7.

41. Chaiopanont S. Hypoglycemic effect of sitting breathing meditation exercise on type 2 diabetes at Wat Khae Nok Primary Health Center in Nonthaburi province. I Med Assoc Thai. 2008:91:93-8.

42. Jung HY Lee H, Park J. Comparison of the effects of Korean mindfulness-based stress reduction, walking, and patient education in diabetes mellitus. Nurs Health Sci. 2015;17:51625

43. Rogers JM, Ferrari M, Mosely K, et al. Mindfulness-based interventions for adults who are overweight or obese: a meta- 
analysis of physical and psychological health outcomes Obes Rev. 2017;18:51-67.

. mindfulness-based stress reduction and mindfulness based cognitive therapy in vascular disease: A systematic review and meta-analysis of randomised controlled trials. J Psychosom Res. 2014;76:341-51.

45. Anderson JW, Liu C, Kryscio RJ. Blood pressure response to transcendental meditation: a meta-analysis. Am J Hypertens. 2008;21:310-6.

46. Jerath R, Barnes VA, Crawford MW. Mind-body response and neurophysiological changes during stress and meditation: central role of homeostasis. J Biol Regul Homeost Agents. 2014;28:545-54.

47. May RW, Bamber M, Seibert GS, et al. Understanding the physiology of mindfulness: aortic hemodynamics and heart rate variability Stress. 2016:19:168-74.
48. Anderson JG, Taylor AG. The metabolic syndrome and mind-body therapies: a systematic review I Nutr Metab. 2011:2011:276419. doi: 10.1155/2011/276419.

49. Carrière K, Khoury B, Günak MM, Knäuper B. Mindfulness-based interventions for weight loss: a systematic review and metainterventions for weight loss: a syste
analysis. Obes Rev. 2018;19:164-77.

50. Cebolla A, Demarzo M, Martins P, et al. Unwanted effects: Is there a negative side of meditation? A multicentre survey. PLOS One. 2017;12:e0183137. doi: 10.1371/journal. pone.0183137

51. Shapiro DH Jr. Adverse effects of meditation: a preliminary investigation of long-term meditators. Int J Psychosom. 1992;39:62-7

52. Walsh R, Roche L. Precipitation of acute psychotic episodes by intensive meditation in individuals with a history of schizophrenia. Am J Psychiatry. 1979:136:1085-6.

53. Banks K, Newman E, Saleem J. An overview of the research on mindfulness-based interventions for treating symptoms of posttraumatic stress disorder a systematic review. I Clin sychol. 2015;71:935-63.

54. Jaseja H. Meditation potentially capable of increasing susceptibility to epilepsy - a follow-up hypothesis. Med Hypotheses. 2006;66:925-8.

55. Kalra S, Sridhar GR, Balhara YP, et al. National recommendations: psychosocial management of diabetes in India. Indian J Endocrinol Metab. 2013;17:376-95,

56. Brook RD, Appel $L$, Rubenfire M, et al. Beyond medications and diet: alternative approaches to lowering blood pressure: a scientific statement from the American Heart Association. Hypertension. 2013;61:1360-83.

57. Levine GN, Lange RA, Bairey-Merz CN, et al. Meditation and cardiovascular risk reduction: a scientific statement from the American Heart Association. J Am Heart Assoc. 2017:6. pii:e002218. doi:10.1161/JAHA.117.002218. 